\title{
Centimeter of Water Times Second per Milliliter
}

National Cancer Institute

\section{Source}

National Cancer Institute. Centimeter of Water Times Second per Milliliter. NCI

Thesaurus. Code C135518.

A unit of measure for pressure change that is expressed by multiplying $\mathrm{cmH} 2 \mathrm{O}$ by seconds, and then dividing that product by the volume of air flow in milliliters 